\title{
Improvement of form accuracy in internal grinding using a slender grinding wheel*
}

\author{
-Prediction of the suitable moment of the wheel retraction in the plunge internal grinding - \\ Takashi ONISHI ${ }^{* *}$, Yuki ODA ${ }^{* *}$, Moriaki SAKAKURA ${ }^{\dagger}$, Yusuke NAKABAYASHI ${ }^{\dagger}$, \\ Kuya NISHI ${ }^{\text {iों }}$ and Kazuhito OHASH ${ }^{* *}$
}

\begin{abstract}
An internal surface of a deep hole is finished by internal grinding. Although the grinding wheel is fed to the axial direction of the workpiece with oscillation in the conventional internal grinding, the end of the wheel wears out. To prevent the intensive wheel wear, we proposed a new internal grinding method. In this method, the grinding wheel was fed to the radial direction and the plunge grinding was carried out by a slender grinding wheel. In this method, the grinding wheel should be retracted at the suitable moment to reduce the internal form error of the ground workpiece. The main cause of the form error is elastic deformation of the grinding wheel, and the wheel runout is also an error factor. The form error of the workpiece was improved with considering two kinds of error factor in the plunge internal grinding with a slender grinding wheel. Furthermore, the profile of the grinding wheel was modified to shorten the grinding cycle time.
\end{abstract}

Key words: internal grinding, slender grinding wheel, high aspect ratio tool, grinding force

\section{Introduction}

Internal grinding is carried out generally as the finishing process of precision components such as inner races of bearings and fuel injection nozzles ${ }^{1)}$. In the case of internal grinding of a deep hole, it is very difficult to finish the ground surface without form error because the stiffness of the tool is $l_{0 w^{2}}^{2), 3}$. In the internal grinding process, the grinding wheel is generally fed to its axial direction as shown in Fig.1(a). In such case, the wheel wear is observed intensively at the end of the grinding wheel because the grinding force is applied intensively at the first interference area between the wheel and the ground workpiece ${ }^{4)}$. To prevent the major wheel wear, we proposed the new grinding method shown in Fig.1(b). This method is plunge grinding by a slender grinding wheel without using the oscillation. The length of the grinding wheel is longer than the ground width and the stiffness of the wheel and wheel axis (quill) are low. In our study ${ }^{5}$, the main cause of the form error is largely caused by the elastic deformation of the grinding wheel as shown in Fig.2. In this grinding method the thermal deformation of the grinding

\footnotetext{
Received on February 28, 2019

Accepted on July 1, 2019

- Full member, Graduate school of Natural Science and technology, Okayama University (3-3-1, Tsushima-naka, Kita-ku, Okayama, 700-8530, Japan)

*. Graduate school of Natural Science and technology, Okayama University, currently at JFE Steel Corporation (22-2-3 Uchisaiwaicho, Chiyoda-ku, Tokyo 100-0011, Japan)

$\uparrow$ Full member, Department of Mechanical and System Engineering, Faculty of Engineering, Daido University (10-3 Takiharucho, Minami-ku, Nagoya, 457-8530, Japan)

\# Graduate school of Natural Science and technology, Okayama University (3-3-1, Tsushima-naka, KIta-ku, Okayama, 700-8530, Japan)

${ }^{\uparrow \uparrow}$ Graduate school of Natural Science and technology, Okayama University, currently at JFE Plant Engineering Co., LTD. (2-17-4 Kuramae, Taito-ku, Tokyo, 111-0051, Japan)
}

wheel and the workpiece were smaller compared with the other previous study ${ }^{6}$, because the aspect ratio of the grinding used in our study was higher than that of the previous study, and the effect of the grinding heat was lower due to the lower plunge speed compare with the previous study. To improve the form accuracy of the internal surface of the ground workpiece finished by the proposed grinding method, the accurate prediction of the wheel retraction moment is essential.

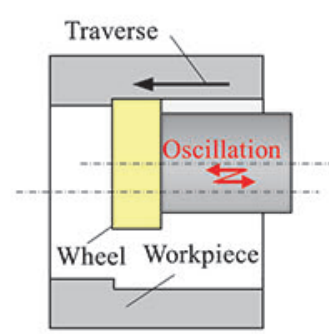

(a) Conventional internal grinding

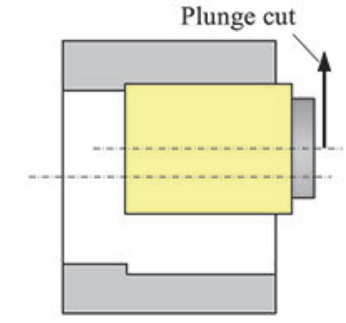

(b) Plunge internal grinding
Fig. 1 Proposed internal grinding method in this study

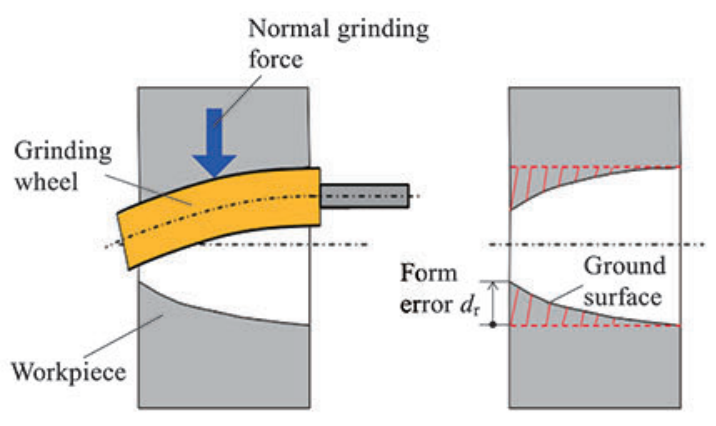

$\begin{array}{ll}\text { (a) During the grinding process } & \text { (b) After the grinding process }\end{array}$

Fig. 2 Form error due to the elastic deformation of the grinding wheel 


\section{Error causes of the plunge internal grinding using a slender grinding wheel}

\subsection{Experimental setup and main grinding conditions}

Figure 3 shows the internal grinding machine used in this study and the sectional view of the interference between the workpiece and the grinding wheel. As shown in this figure, the aspect ratio of the grinding wheel is approximately four. Table 1 shows the main grinding conditions. The spark-out duration, that has an important influence on the ground profile, was changed arbitrarily.

\subsection{Effect of the spark-out duration}

Figure 4 shows the measured results of the normal grinding force when the spark-out duration $\tau$ was changed. During the rough and the fine grinding process, the elastic deformation of the grinding wheel decreased in proportion to the normal grinding force fell. During the spark-out process, the normal grinding force decreased as the spark-out duration passed because the residual stock removal decreased. Therefore, the form error of the ground surface improved as the spark-out duration passed as shown in Fig. 5. Before grinding, the form error of the workpiece was less than $3 \mu \mathrm{m}$. Figure 5 shows the measured profile of the ground workpiece in each grinding experiment. These figures suggest the existence of a suitable normal grinding force to retract the grinding wheel.

\subsection{Elastic deformation of the grinding wheel}

As mentioned before, the main cause of the form error is the elastic deformation of the grinding wheel. To estimate the elastic deformation of the grinding wheel, the spring rate of the grinding wheel was measured as shown in Fig. 6. As shown in Fig.6, the force is applied to the center of the ground part. The elastic deformation of the wheel was measured by electric micrometers.

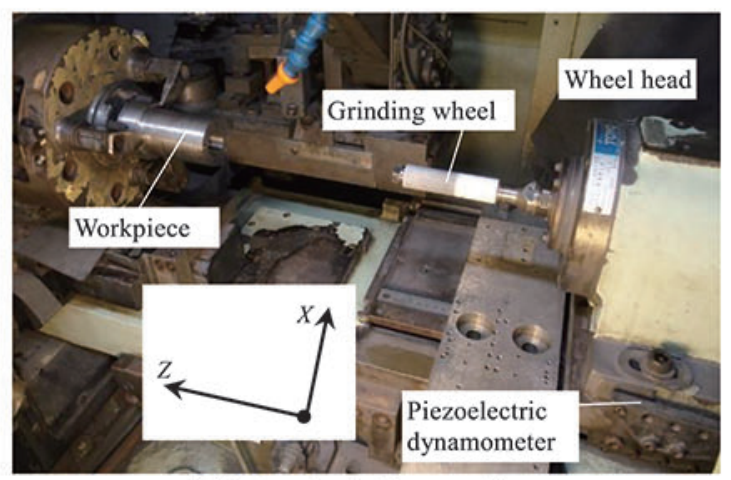

(a) Internal grinding machine

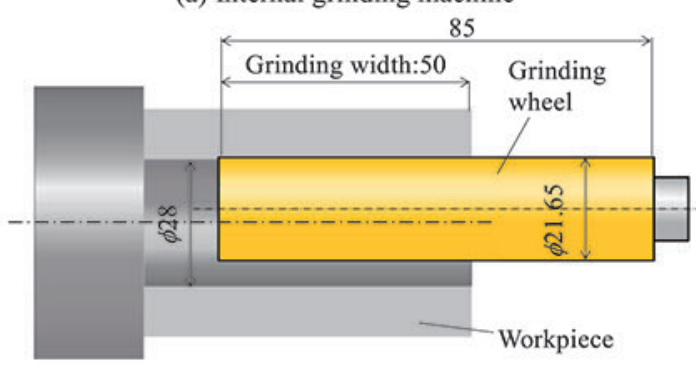

(b) Sectional view of the workpiece and the grinding wheel

Fig. 3 Experimental setup used in this study
Figure 7 shows the measured results of the elastic deformation $d_{\mathrm{If}}$ and $d_{\mathrm{lr}}$ at the tip and the rear end of the grinding part of the

Table 1 Main grinding conditions

\begin{tabular}{c|c}
\hline Grinding wheel & SA120K8V $\phi 21.65 \times 85 \mathrm{~mm}$ \\
\hline Grinding width & $b=50 \mathrm{~mm}$ \\
\hline Workpiece & S45C \\
\hline Wheel peripheral speed & $V_{\mathrm{s}}=17.0 \mathrm{~m} / \mathrm{s}$ \\
\hline Workpiece peripheral speed & $V_{\mathrm{w}}=1.03 \mathrm{~m} / \mathrm{s}$ \\
\hline Plunge Speed (Rough) & $V_{\mathrm{p} 1}=3.0 \mu \mathrm{m} / \mathrm{s} \quad(t<30.4 \mathrm{~s})$ \\
\hline Plunge Speed (Fine) & $V_{\mathrm{p} 2}=0.5 \mu \mathrm{m} / \mathrm{s}(30.4 \leqq t<38.5 \mathrm{~s})$ \\
\hline Spark-out duration & $\tau=10$ to $120 \mathrm{~s}$ \\
\hline Dressing Condition & $5 \mu \mathrm{m} \times 5 \mathrm{pass}$ \\
\hline \multirow{2}{*}{ Flow of coolant } & Wheel side $6.20 \mathrm{~L} / \mathrm{min}$ \\
\cline { 2 - 2 } & Chuck side $5.95 \mathrm{~L} / \mathrm{min}$ \\
\hline
\end{tabular}
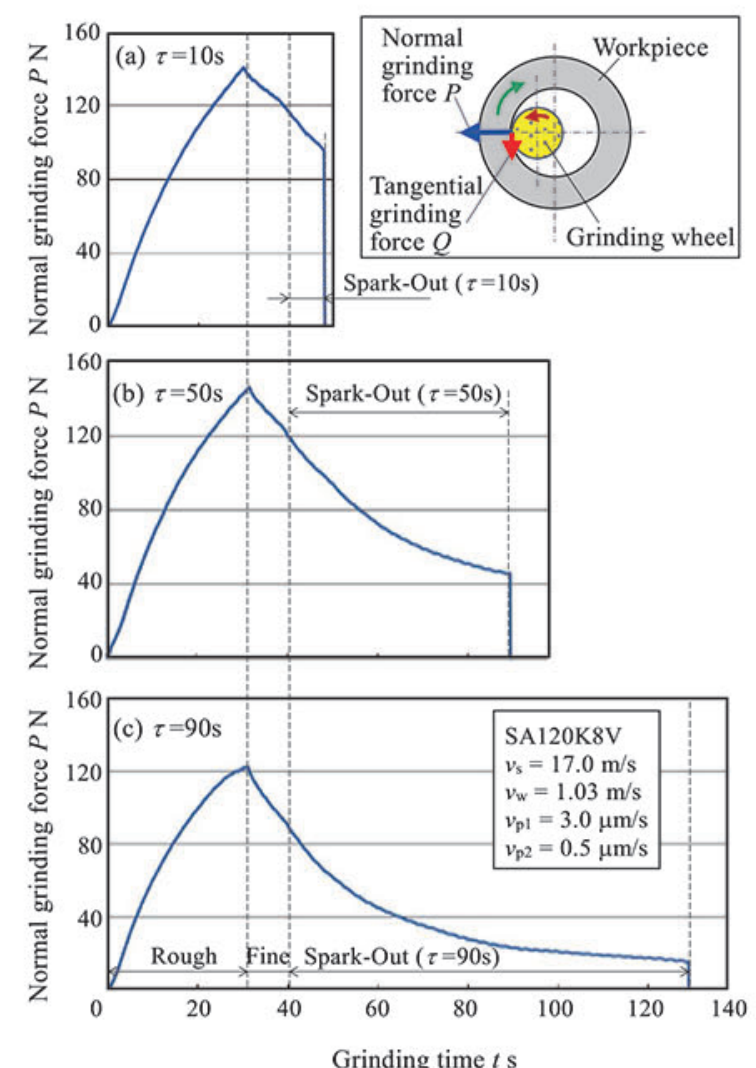

Fig. 4 Change in the normal grinding force during the grinding process

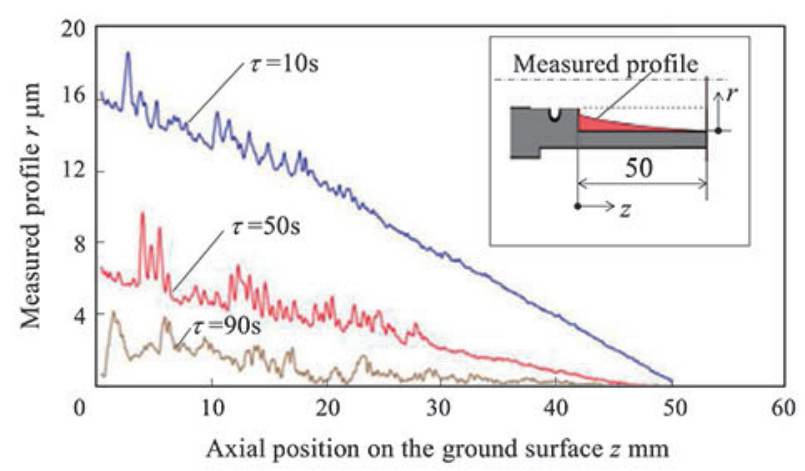

Fig. 5 Measured profile of the ground surface with changing the spark-out duration 
wheel respectively. From this figure, the elastic deformation of the grinding wheel $d_{1}$ along the grinding part is estimated from equation (1).

$$
d_{1}=P / k_{1}
$$

Where $k_{1}$ is the spring rate of the wheel, and $P$ is the measured normal grinding force. The spring rate $k_{1}$ was calculated by equation (2).

$$
k_{1}=P /\left(d_{1 \mathrm{f}}-d_{\mathrm{lr}}\right)
$$

From the results shown in Fig.7, the spring rate was determined as $4.59 \mathrm{~N} / \mu \mathrm{m}$. The elastic deformation that affects the form error can be calculated by dividing the normal grinding force measured at the wheel retraction moment by the spring ratio $k_{1}$.

Figure 8 shows the comparison between the measured form error of the ground workpiece and the estimated elastic deformation that was calculated from the normal grinding force $P_{\mathrm{o}}$ when the wheel was retracted. As mentioned before, the force $P_{\mathrm{o}}$ decreased and form error was improved when the spark-out duration was expanded. In this figure, there is a difference less than $5 \mu \mathrm{m}$ between the estimated and measured results. The difference could be due to the wheel runout as shown in Fig.9.

\subsection{Wheel runout}

To measure the wheel runout, the workpiece prepared by painting inside with red ink as shown in Fig.10(a). As the grinding wheel was fed to the radial direction, the inked surface was removed first by the tip of the wheel. The radial position of the wheel where the ink removal was observed first defined as $d$ $=0$. This result demonstrates that the tip of the wheel rotated eccentrically due to the wheel runout. The wheel was fed into the workpiece surface beyond the setting. When the wheel reached to $d=2.5 \mu \mathrm{m}$, almost all of the workpiece was ground. But the surface located to the wheel head side was still not ground. The

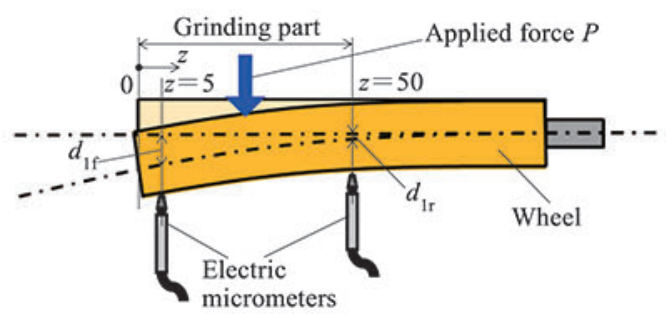

Fig. 6 Measurement of the spring rate of the grinding wheel

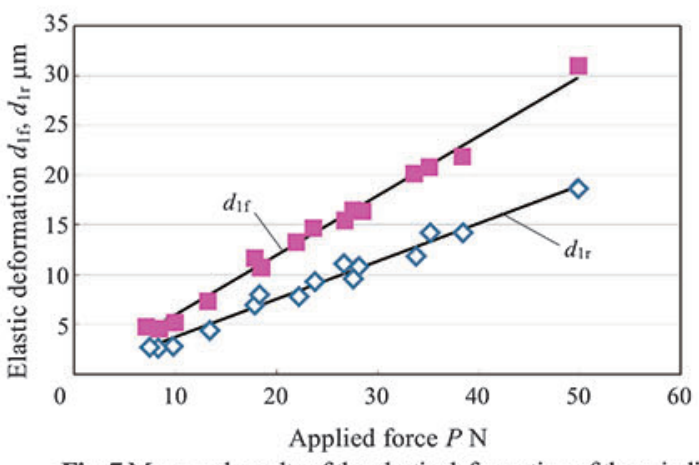

Fig. 7 Measured results of the elastic deformation of the grinding wheel wheel was fed to $d=3 \mu \mathrm{m}$, the painted area was not observed. From those results, the wheel run out $e_{\mathrm{s}}$ was determined $-3 \mu \mathrm{m}$.

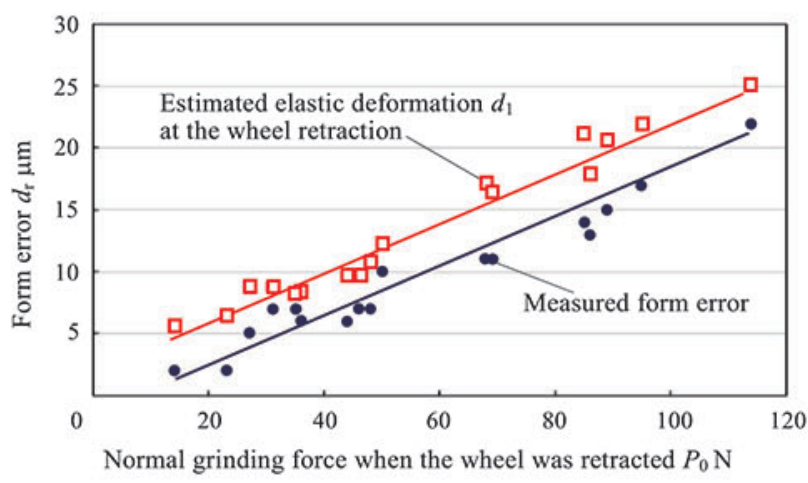

Fig. 8 Comparison between the measured form error and the estimated elastic deformation at the wheel retraction

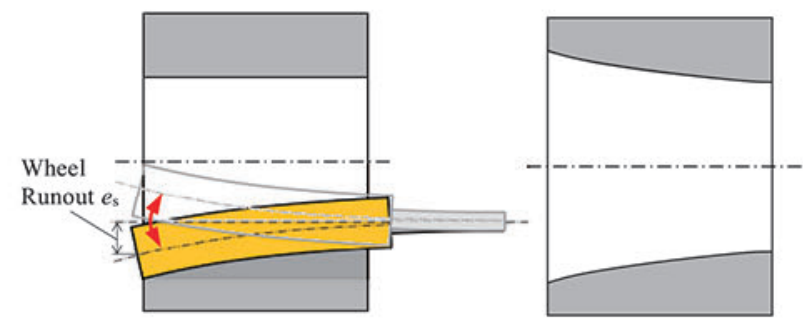

(a) During the grinding process (b) After the grinding process Fig. 9 Effect of the wheel runout

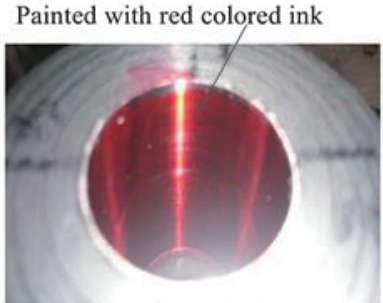

(a) Before grinding

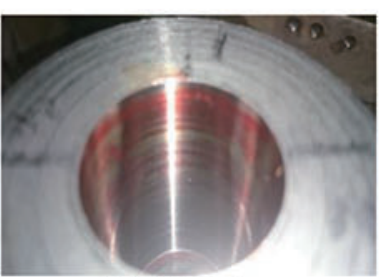

(c) $d=2.5 \mu \mathrm{m}$

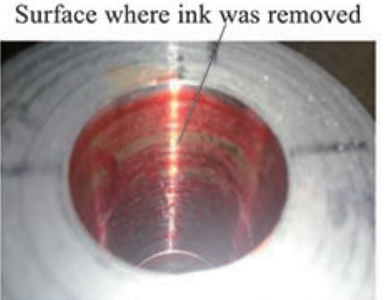

(b) $d=0$ (First removal of ink)

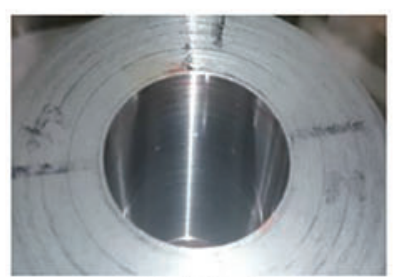

(d) $d=3 \mu \mathrm{m}$
Fig. 10 Observation of the wheel nunout (View from wheel head side)

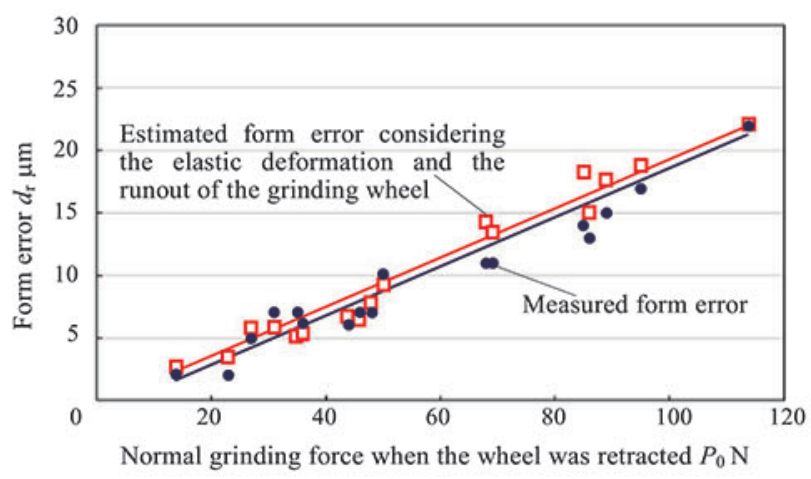

Fig. 11 Estimated form error of the ground workpiece with considering the elastic deformation and the runout of the grinding wheel 


\subsection{Estimation of the form error}

Figure 11 shows the comparison between the measured form error of the ground workpiece and the estimated form error considering the elastic deformation of the grinding wheel caused by the normal grinding force and the wheel runout $e_{\mathrm{s}}$. The estimated form error $d_{\mathrm{r}}$ was obtained from equation (3).

$$
\begin{aligned}
d_{\mathrm{r}} & =d_{1}+e_{\mathrm{s}} \\
& =P / k_{1}+e_{\mathrm{s}}
\end{aligned}
$$

From equation (3) the normal grinding force when the form error $d_{\mathrm{r}}$ is minimized can be calculated by assigning 0 to $d_{\mathrm{r}}$. The form error is minimized by retracting the grinding wheel at the moment when the normal grinding force is reached to the value calculated form equation (4).

$$
P_{0}=-k_{1} e_{\mathrm{s}}
$$

\section{Grinding experiments with monitoring the normal grinding force}

\subsection{Prediction of the normal grinding force that can minimize the form error}

From equation (3), the normal grinding force $P_{0}$ that can minimize the form error was $13.8 \mathrm{~N}$ by multiplying the spring ration $k_{1}=4.59 \mathrm{~N} / \mu \mathrm{m}$ and the wheel runout $e_{\mathrm{s}}=-3 \mu \mathrm{m}$. To evaluate the prediction accuracy, grinding experiments were carried out twice. In the first grinding experiment, the form error before grinding $d_{\mathrm{r} 0}$ was $-2.9 \mu \mathrm{m}$ as shown in Fig.12(a). In the second grinding experiment, the form error $d_{\mathrm{r} 0}$ was $3.3 \mu \mathrm{m}$ as shown in Fig.12(b). In each grinding experiment, the grinding wheel was retracted at the spark-out process when the normal grinding forces were reached to predicted value $P_{0}$ during spark-out process.

Measured grinding forces are shown in Fig.13. In each grinding process, the wheel was retracted when the normal grinding forces were close to the predicted value. Figure 14 shows the internal profiles measured after the grinding. In the first and the second grinding experiment, the form error was less than $2 \mu \mathrm{m}$ and $1 \mu \mathrm{m}$ respectively. The spark-out duration was longer in the second grinding experiment accordingly the form error was reduced successfully. Figure 15 shows the profiles of the wheel measured before and after the grinding experiments. In the first grinding experiment, the large form error was observed at the wheel profile. In this study, the effect of the wheel wear was not considered, therefore, the form error still remained.

\subsection{Reduction of the spark out duration using the grinding wheel with modified profile}

As shown in Fig.13, the spark-out duration was excessively long in the proposed method. Therefore, the profile of the grinding wheel was modified to shorten the spark-out duration. Figure 16(a) shows the grinding wheel with modified profile. By using this wheel, it was expected that the elastic deformation is compensated and the wheel can be retracted even though the normal grinding force does not increase as shown in Fig. 16(b). Figure 17 shows the overview of the tooling to modify the wheel profile. The diamond dresser was directed to the radial direction in synchronization with the feed motion of the grinding wheel to the axial direction.

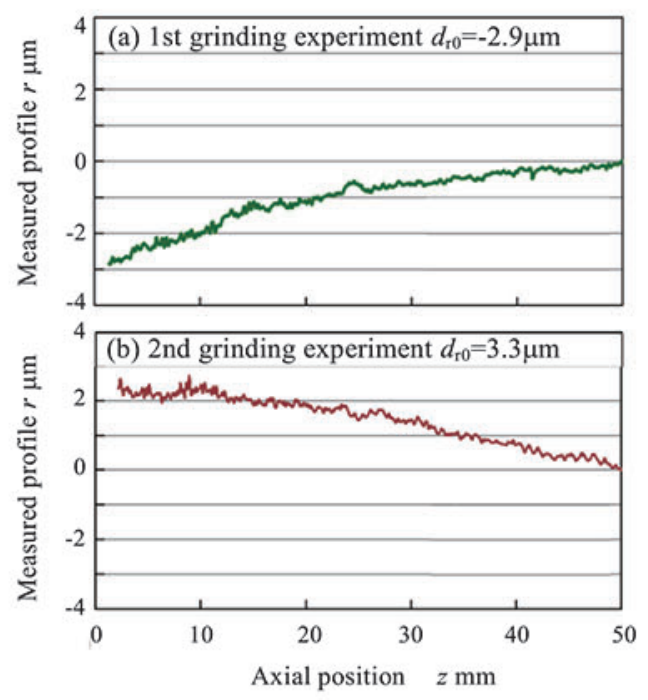

Fig. 12 Measured internal profiles of the workpiece before experiments
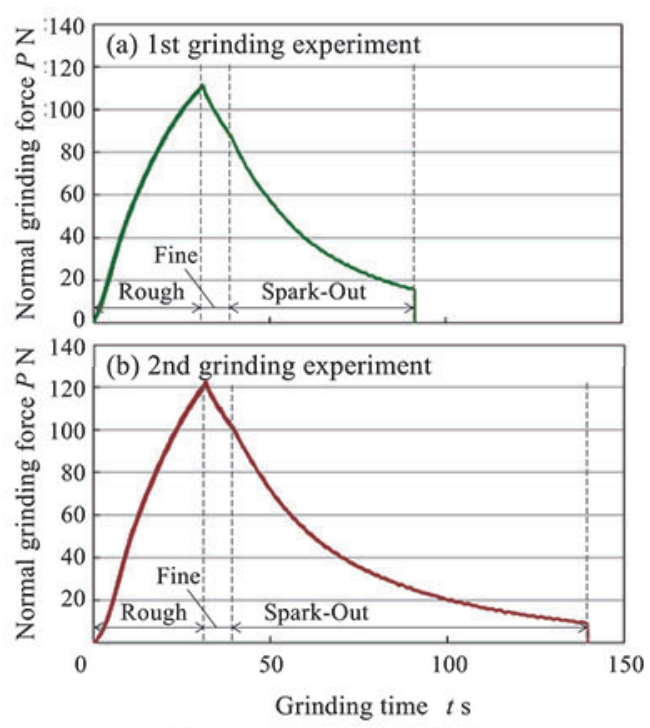

Fig. 13 Measured normal grinding forces
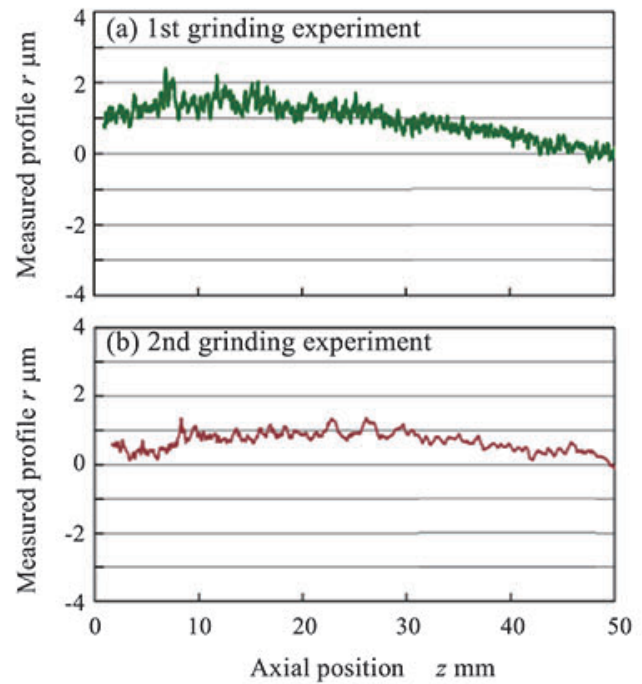

Fig. 14 Measured internal profiles of the workpiece after experiments 

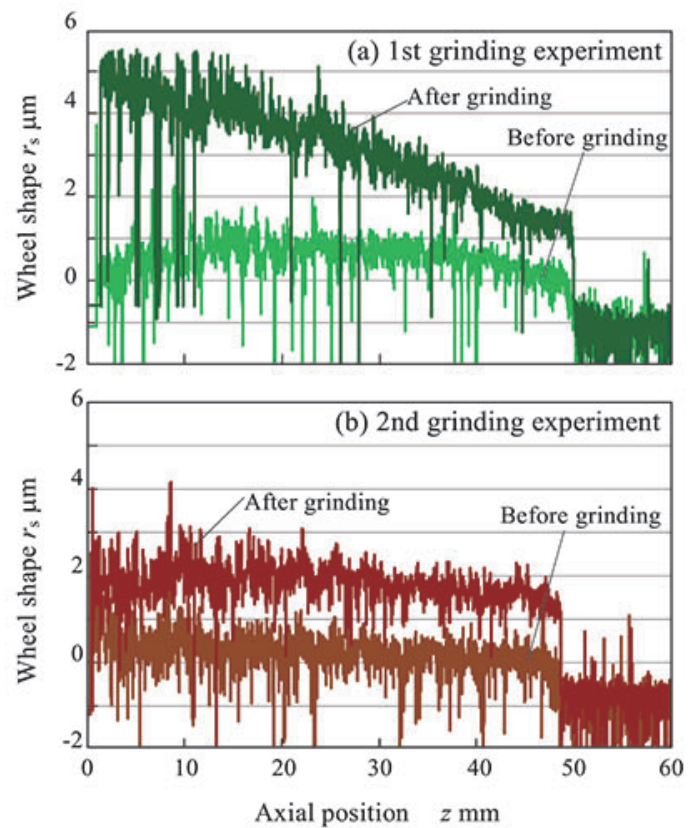

Fig. 15 Measured profile of the grinding wheel

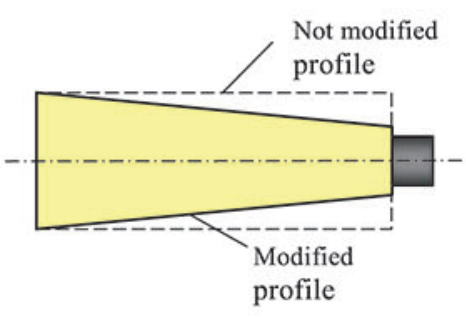

(a) Profile modification of the wheel

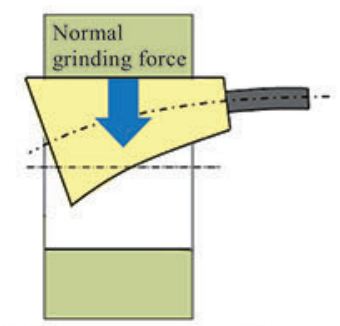

(b) Compensation of the elastic deformation
Fig. 16 Internal grinding by the wheel with modified profile

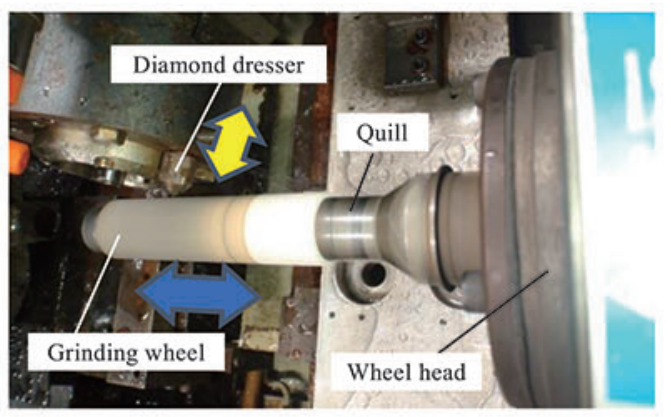

Fig. 17 Overview of the profile modification with a diamond dresser

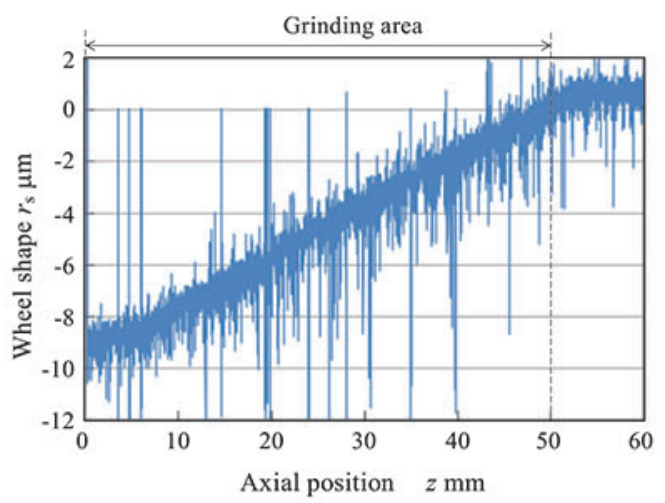

Fig. 18 Measured profile of the tooled wheel
Figure 18 shows the profile of the grinding wheel. The amount of the taper was $9 \mu \mathrm{m}$ along the grinding width. Integrating the wheel runout $e_{\mathrm{s}}=3 \mu \mathrm{m}$, the grinding wheel should be retracted when the elastic deformation of the wheel is $12 \mu \mathrm{m}$ to compensate the wheel runout and the tapered profile. Therefore, the predicted normal grinding force $P_{0}$ was set to $55.1 \mathrm{~N}$.

3.3 Result of the grinding experiment by the wheel with profile modification

Figure 19 shows the change in normal grinding force. In this experiment, wheel was retracted at the moment when the normal grinding force was down to $55.2 \mathrm{~N}$. The spark out duration $\tau$ is approximately 15 seconds. Figure 20 shows the measured profile of the ground workpiece. The form error of the ground workpiece was less the $1 \mu \mathrm{m}$. Figure 21 is the profile of the grinding wheel measured after grinding experiment. By comparing Fig.20 and Fig.21, it was confirmed that the wheel wear uniformly generated

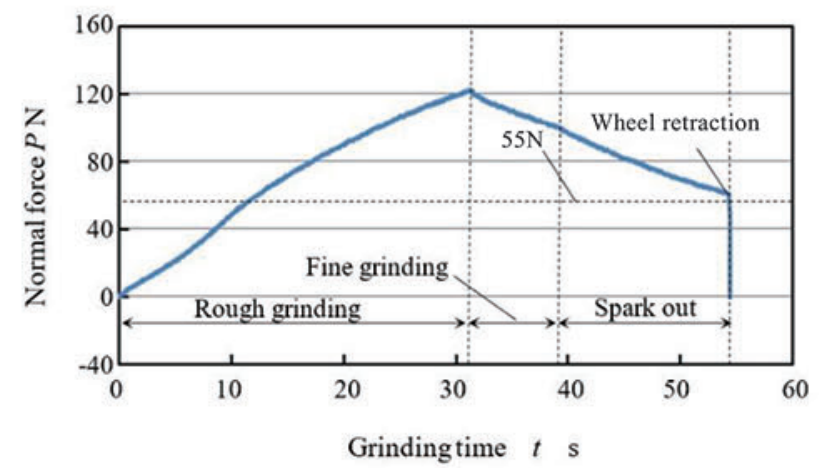

Fig. 19 Measured normal grinding force

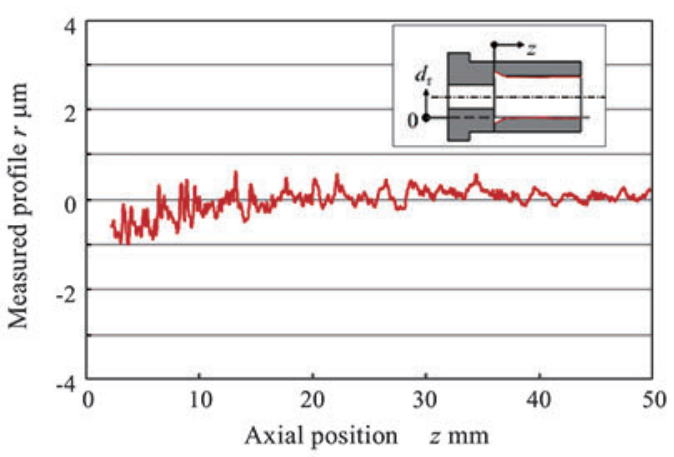

Fig. 20 Profile of the workpiece ground by modified wheel

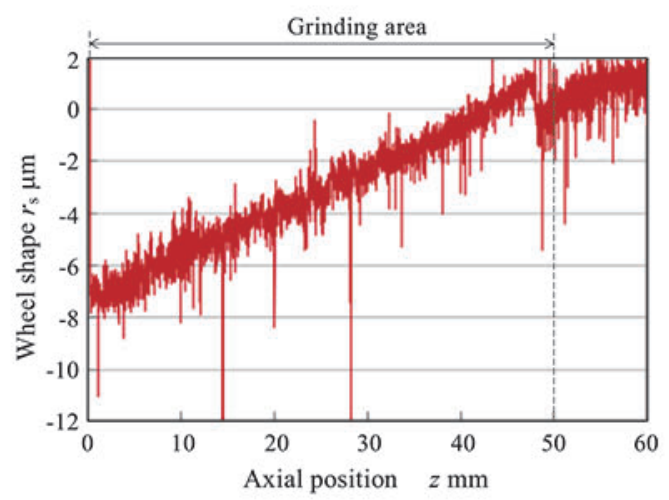

Fig. 21 Profile of the grinding wheel measured after the grinding experiment 
along the wheel axis. In this case, wheel wear did not affect the form accuracy of the ground workpiece. By using the profile modification of the grinding wheel, the form accuracy was improved in a short spark out duration successfully.

\section{Conclusions}

In this study, a new internal grinding method was proposed to improve the form accuracy using a slender grinding wheel. Main conclusions in this study are as follows:

(1) It was confirmed that the cause of the form error in plunge internal grinding was not only the elastic deformation of the workpiece but also the wheel runout.

(2) In plunge internal grinding, the normal grinding force that can compensate the wheel runout was estimated successfully.

(3) The modification in the wheel profile reduces the grinding cycle time without increasing the form error of the ground workpiece.

\section{Acknowledgement}

We are grateful to MIZUHO Co., Ltd. for their assistance of providing the grinding wheels with special specification.

\section{References}

1) F. Brusiani et al.: Influence of the Diesel injector hole geometry on the flow conditions emerging from the nozzle, Energy Procedia, 45, (2014) 749.

2) K. Yamauchi, J. Takagi: Study on Internal Grinding of Small Bore, Proceedings of the 10th International Conference on Precision Engineering, (2002) 466.

3) S. Tsukamoto et al.: Development of Controlled Internal Oscillation Grinding for Optimal Geometrical Accuracy of Deep Straight Hole, Journal of JSPE, 70, 2, (2004) 263 (in Japanese).

4) K. Okamura et al.: Study of Traverse Grinding Process (2nd Report), Journal of JSPE, 46, 6, (2004) 753 (in Japanese).

5) T. Onishi et al.: Improvement of accuracy in internal grinding with shape modification on high aspect ratio wheel, Proceedings of LEM21, (2011) 3277.

6) T. Nakajima et al.: Behavior of Thermal Deformations of Wheel and Workpiece and Form Generation Mechanism in Internal Grinding Process, Journal of JSPE, 61, 1, (1995) 127 (in Japanese). 